\title{
A Non-Permanent Tonic Pupil in Rheumatoid Arteritis
}

\author{
DAVID I. VICTOR, W. RICHARD GREEN, WALTER J. STARK
}

AND FRANK B. WALSH

SUMMARY: $A$ 76-year-old male with a severely deforming rheumatoid arthritis, eosinophilia, polymyositis, and episcleritis developed a transient tonic pupil. The episcleritis, and a mascle biopsy revealing an occlusive arteritis with eosinophilia, suggest that a widespread rheumatoid arteritis caused a reversible ischemic insult to the ciliary ganglion and thus created a transient denervation of the pupil.

RÉSUMÉ: Une homme de 78 ans souffrant d'arthrite rhumatö̈de déformante sévère, d'eosinophilie, de polymyosite et d'épisclérite a développé une pupille tonique transitoire. L'épisclérite, et une biopsie du muscle révélant une artérite obstructive avec eosinophilic, suggèrent qu'une artérite rhumatö̈le généralisée causait une lésion ischémique réversible an ganglion ciliaire et ainsi créait une dénervation transitoire de la pupille.

From the Eye Pathology Laboratory, Wilmer In stitute and Department of Pathology, The Johns Hopkins Medical Institutions, Baltimore, Maryland.

Reprint requests to: Dr. W. R. Green, Eye Pathology Laboratory, The Johns Hopkins Hospital, 601 N. Broadway, Baltimore, Maryland 21205 .

\section{INTRODUCTION}

The tonic pupil, to our knowledge, has been reported only once in association with the arteritis of rheumatoid arthritis (Littlewood and Lewis, 1963). In addition, the tonic pupil is not usually reversible. The purpose of this paper is to report a patient with rheumatoid arthritis who developed a reversible tonic pupil, and to discuss the pathogenesis of this disorder.

\section{CASE REPORT}

This 76-year-old man was admitted to The Johns Hopkins Hospital for the first time, complaining of severe joint pain and swelling. He had been in excellent health until three years before admission when he developed pain and stiffness in his elbows, wrists, and hands, with subsequent development of rheumatoid deformities. He had been treated for this with aspirin, Indomethacin $\circledast$. and corticosteroids. Six months before admission the corticosteroids were discontinued because of gastrointestinal hemorrhage, and exacerbation of the arthritis occurred. Two months before admission the patient developed redness and pain to touch in each eye. Past ophthalmic history was normal.

Physical Examination: Prominent rheumatoid deformities of the hands and feet were present (Fig. 1). There was proximal weakness of the upper and lower extremities, with intact reflexes and sensation.

Visual acuity was $20 / 30$ in each eye. Prominent episcleral injection (Fig. 2) and tenderness to touch were present in both eyes. The right pupil was $3 \mathrm{~mm}$ and briskly reactive to stimulus and the left was $4 \mathrm{~mm}$ and sluggishly reactive (Fig. 3). Methacholine (Mecholyl®. 2.5\%) did not affect the right pupil but contracted the left to $2.5 \mathrm{~mm}$. Extraocular movements were normal. Flare $(1+)$ and trace cells were present in the anterior chambers bilaterally, and $1+$ lenticular opacities were present bilaterally. Intraocular pressure and funduscopy were normal.

Complete blood count and urinalysis were normal except for the eosinophil count, which was $2255 / \mathrm{cu} \mathrm{mm}$. Blood sedimentation was $65 \mathrm{~mm} / \mathrm{hr}$., antinuclear antibody was positive at $1 / 40$, and latex fixation was positive at $1 / 5,120$. Serum IgM was $290 \mathrm{mg} / \mathrm{ml}$ (normal, 48-164), with no $\operatorname{IgG}$ or $\operatorname{IgA}$. The C'3 complement component was 11 (normal, 11-75).

Nerve conduction studies and electromyography were normal. Muscle biopsy of the gluteal muscles revealed a prominent occlusive arteritis (Fig. 4) with an inflammatory-cell infiltration consisting of large mononuclear cells, lymphocytes, numerous eosinophils

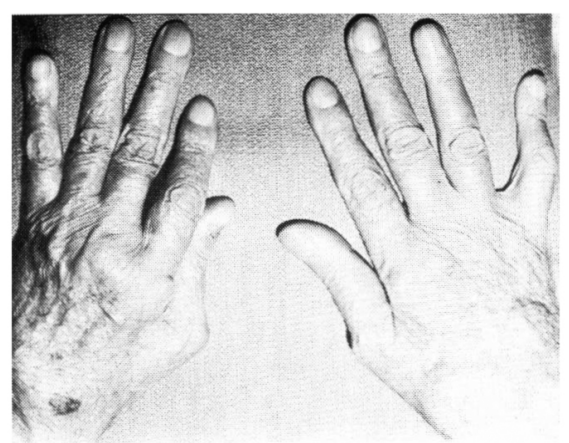

Figure 1-Moderately severe rheumatoid deformities of the hands. 

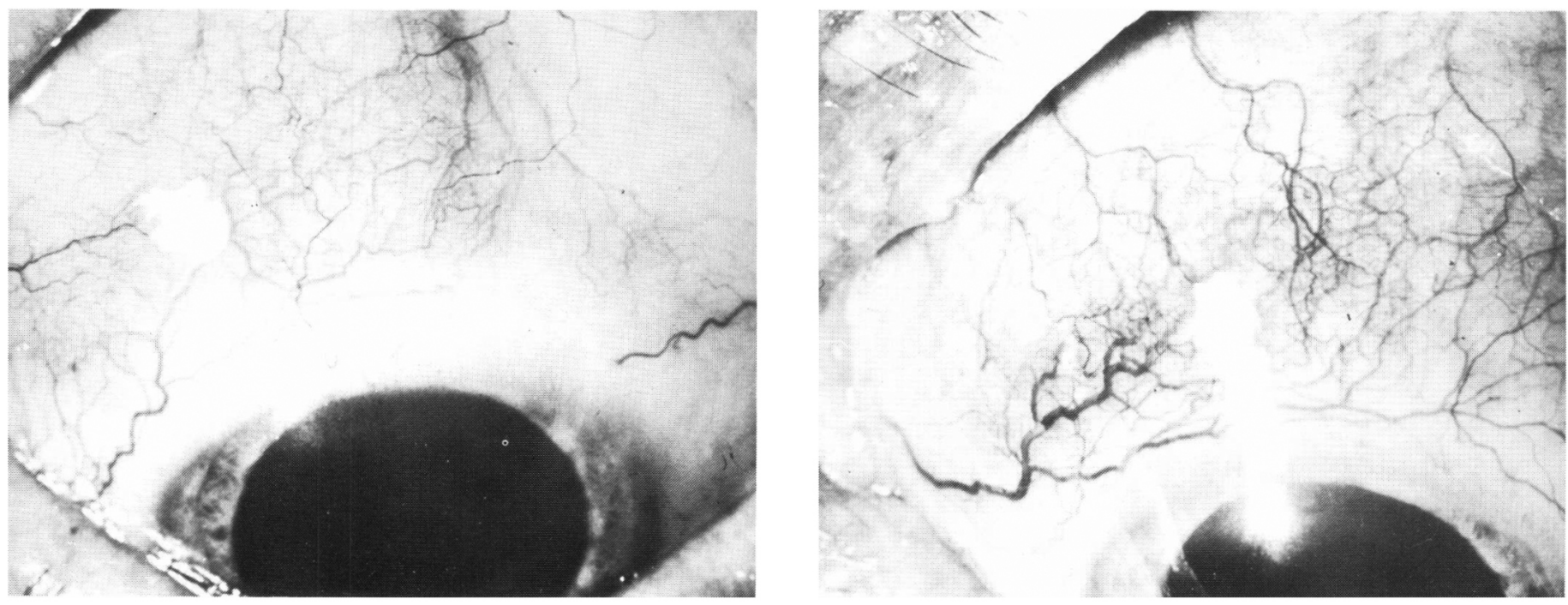

$A$.

Figure 2-Episcleritis of the right eye (A) and left eye (B).

and occasional epithelioid cells. Some smaller arteries had a prominent perivascular inflammatory infiltration (Fig. 5). Adjacent adipose tissue contained gold deposits within macrophages (Fig. 6).

Hospital Course: The patient was treated with topical and systemic corticosteroids, with some improvement in his strength and with relief of episcleral injection. Within three months the pupils were almost the same size bilaterally, and both reacted briskly and equally (Figs. $7 \mathrm{~A}, \mathrm{~B})$ on direct and consensual stimulus. Methacholine $(2.5 \%)$ no longer resulted in pupillary constriction.

\section{DISCUSSION}

Clinical and laboratory evidence, including a biopsy revealing an occlusive necrotizing vasculitis, suggests that the arteritis of rheumatoid arthritis in our patient resulted in an ischemic insult to the episclera and nearby ciliary ganglion, creating a reversible episcleritis and tonic pupil.
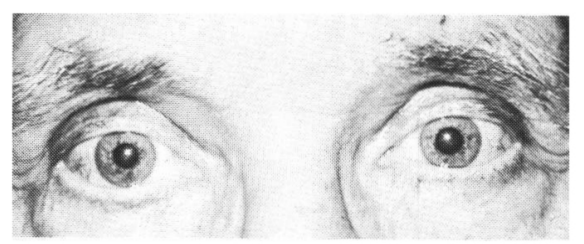

Figure 3-The dilation of the left pupil is unresponsive to direct and consensual light stimulation.
The tonic pupil usually presents as a unilateral dilated pupil that responds to direct light stimulation with a slow, tonic contraction and later slow dilation. The accommodative response is often less slow and more nearly complete. Unlike the normal pupil, the tonic pupil will respond to $2.5 \%$ methacholine with constriction (Lowenstein and Loewenfeld, 1965). In our case the tonic pupil was established by the fact that the affected pupil did not respond to direct or consensual light stimulation, but did contract in response to $2.5 \%$ methacholine.

It was through Adie's publications that the tonic pupil became known (Lowenstein and Loewenfeld, 1965). This knowledge helped to differentiate the pupillary changes of a condition that is usually quite benign from those of more serious disorders involving the pupil, especially intracranial aneurysms and syphilis. However, since Adie's reports, the tonic pupil has been reported to occur in association with a variety of disease states, including mechanical and chemical trauma, acute and post-acute viral infections, orbital masses, and autonomic dystrophies. However, the tonic pupil has been reported in association with only one case of arteritis and that was a case of giant-cell arteritis (Davis et al., 1968). As noted before, the tonic pupil has, to our knowledge, been previously reported in association with rheumatoid arthritis only once (Littlewood and Lewis, 1963). In that case, a 7-year-old boy developed a unilateral tonic pupil and absent deep tendon reflexes 6 days after the onset of an acute attack of juvenile rheumatoid arthritis. The involved pupil remained tonic 6 months after the attack.

By contrast, both episcleritis and scleritis are most commonly associated with rheumatoid arthritis, although they also occur with a variety of collagen diseases, and several skin disorders, including psoriasis and lichen planus (Lyne and Pitkeathley, 1968). Since Scheie and Adler discussed the fact that methacholine provided miosis in the affected eye, it has been agreed that the site of damage in the tonic pupil syndrome is the ciliary body. The presence of episcleritis and scleritis suggests that the nearby ciliary ganglion and the short posterior ciliary nerves, as well as the sclera and episclera, were involved with the rheumatoid arteritis in our case.

The usual character of rheumatoid vasculitis is a mononulcear vascular cuffing, fibrotic thickening, and intimal proliferation of small-sized arteries and veins; but a necrotizing arteritis may also be seen (Schmid et al., 1961). A similar necrotizing vasculitis may be seen in 1) other collagen disease; 2) the allergic granulomatous arteritis of Churg and Strauss; 3) rheumatic fever; 4) 


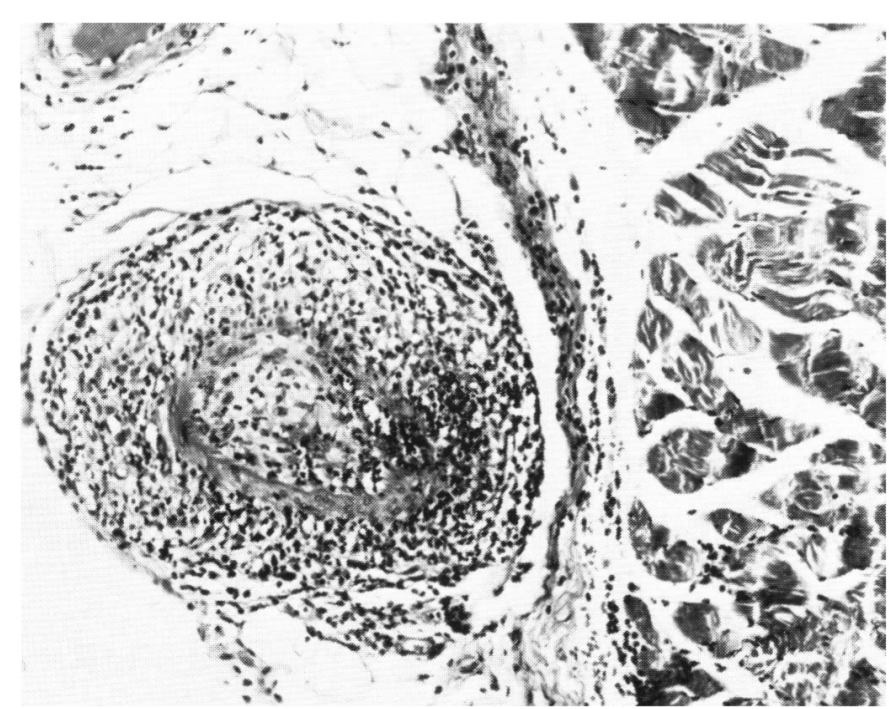

Figure 4-Gluteal muscle biopsy revealing an occlusive vasculitis. Hematoxylin and eosin, X 100.

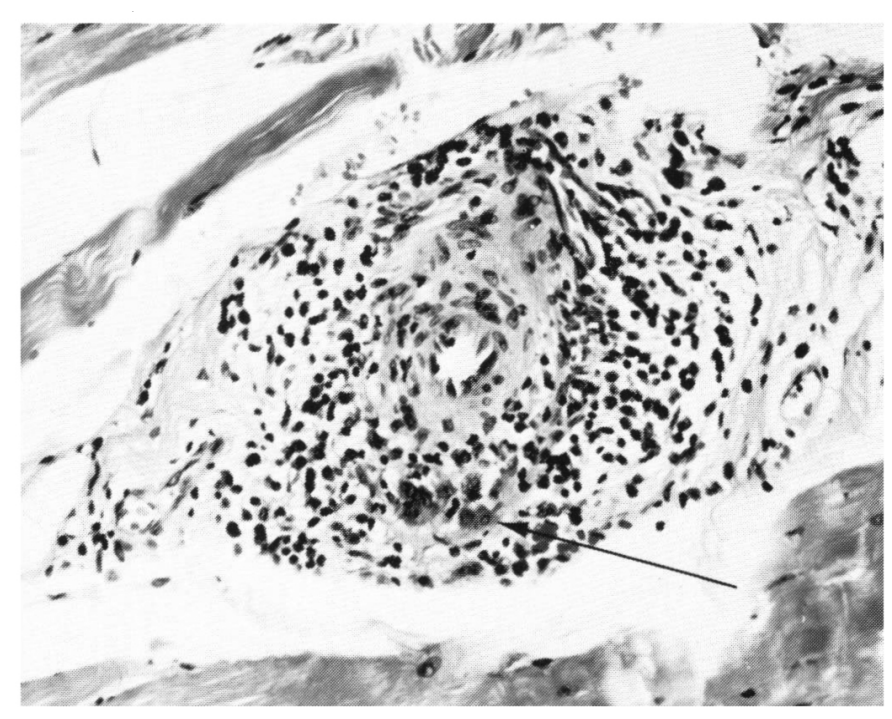

Figure 5-Smaller artery with an intensive perivascular infiltration of lymphocytes, occasional epithelioid cells (arrow) and numerous eosinophils. Hematoxylin and eosin, X 180. hypersensitivity angitis; and 5) hypertension (Farooki et al., 1974). The most severe necrotizing changes are seen in polyarteritis nodosa, in which aneurysmal formation and perivascular nodule formation may occur (Zeck, 1953). However, in some cases of clinically-pure rheumatoid arthritis, polyarteritislike changes can be seen (Zeek, 1953; Ramos and Mandybur, 1975). Clinically, when a necrotizing arteritis is present in rheumatoid arthritis, occurrence of episcleritis, polymyositis, and polyneuritis are more frequent (Zeek, 1953; Panush et al., 1971). The former two were present in our patient.

As with our patient, when eosinophilia is found with rheumatoid arthritis, arteritis (especially the necrotizing variety) is much more likely to be present, associated with severe deforming articular disease, pleuritis, and sub- cutaneous nodules, as well as hypocomplementemia and elevated IgM antibody (Steinburg and Parry, 1961). All of these were present in our patient. Since eosinophilia is a prominent part of the polyarteritis nodosa syndrome, the clinical distinction between rheumatcid arthritis with eosinophilia versus polyarteritis nodosa may be difficult. However, the absence of renal and peripheral nerve involvement does not favor the diagnosis of polyarteritis nodosa.

The tonic pupil response usually persists indefinitely, although its size may change at irregular intervals and there is a tendency for it to become smaller. In our patient, recovery appeared complete, although this was not documented with pupillographic recordings. Since the tonic pupil syndrome usually persists, why did our_patient recover moreor-less completely? The answer

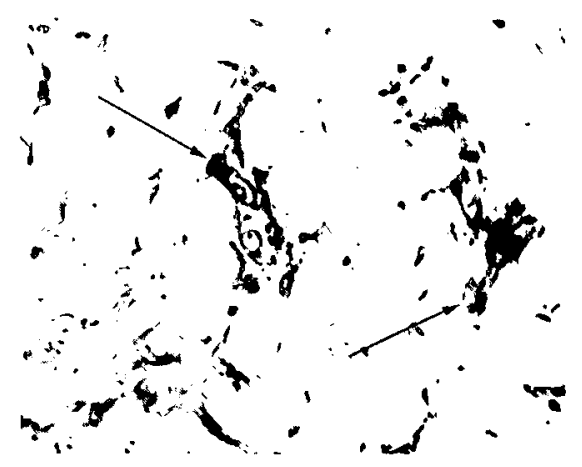

Figure 6-Muscle biopsy showing gold deposits (arrows) within macrophages in adipose tissue. Hematoxylin and eosin. X 260.

must lie in the nature of the insult to the ciliary ganglion. In the usual case of tonic pupil, an inflammatory polyneuritis is thought to destroy most of the ciliary ganglion. With time, the remaining neurons, which originally had innervated mainly the ciliary body, now reinnervate the
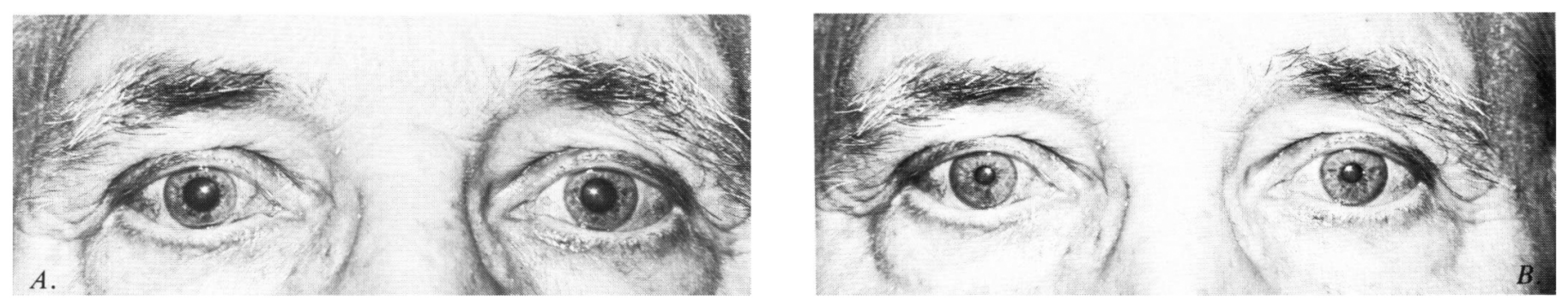

Figure 7-Recovery from tonic pupil, left eye. The pupillary size is equal bilaterally in this photograph taken 12 months after the start of therapy; (A) in dark, (B) in light. 
pupil also. In our patient, the damage was incomplete and thus reversible. This is entirely consistent with the hypothesis of an ischemic insult, secondary to the widespread rheumatoid vasculitis. In both persisting and reversible cases, there is a denervation of the pupil, resulting in a tonic pupil.

\section{REFERENCES}

DAVIS, R. H., DAROFF, R. B. and HOYT, W. F. (1968). Tonic pupil after temporal arteritis. Lancet 1: 822 .
FAROOKI, Z. Q., BROUGH, A. J. and GREEN, E. W. (1974). Necrotizing arteritis. Am. J. Dis. Child 128: 837-840.

LITTLEWOOD, J. M. and LEWIS, G. M. (1963). The Holmes-Adie syndrome in a boy with acute juvenile rheumatism and bilateral syndactyly. Arch. Dis. Child 38: 86-88.

LOWENSTEIN, $O$. and LOEWENFELD, I. E. (1965). Pupillotonic pseudotabes. Survey Ophthalmol. 10: 129-185.

LYNE, A. J. and PITKEATHLEY, D. A. (1968). Episcleritis and scleritis. Arch. Ophthalmol. 80: 171-176.

PANUSH, R. D., FRANCO, A. E. and SCHUR, P. H. (1971). Rheumatoid arthritis associated with eosinophilia. Ann. Intern. Med. 75; 199-205.

RAMOS, M. and MANDYBUR, T. I. (1975). Cerebral vasculitis in rheumatoid arthritis. Arch. Neurol. 32: 271-275.

SCHMID, F. R., COOPER, N. S., ZIFF, M. and McEWEN, C. (1961). Arteritis in rheumatoid arthritis. Am. J. Med. 30: 56-83.

STEINBURG, V. L. and PARRY, C. B. (1961). Electromyographic changes in rheumatoid arthritis. Br. Med. J. 5226: 630-632.

ZEEK, P. M. (1953): Periarteritis nodosa and other forms of necrotizing angitis. New Eng. J. Med. 248: 764-772. 